\title{
Commentary \\ Monocyte TREM-1 membrane expression in non-infectious inflammation
}

\author{
Jean-Marc Cavaillon
}

Unit Cytokines \& Inflammation, Institut Pasteur, 28 rue Dr Roux, 75015 Paris, France

Corresponding author: Jean-Marc Cavaillon, jean-marc.cavaillon@pasteur.fr

Published: 1 June 2009

Critical Care 2009, 13:152 (doi:10.1186/cc7882)

This article is online at http://ccforum.com/content/13/3/152

(c) 2009 BioMed Central Ltd

See related research by Ferat-Osorio et al., http://ccforum.com/content/13/3/R69

\begin{abstract}
Sterile or non-infectious inflammation and severe infection are accompanied by very similar events. Damage (or danger)associated molecular patterns and pathogen-associated molecular patterns trigger the release of inflammatory mediators and modulate the expression of cell surface receptors. The increased expression on monocytes and neutrophils of triggering receptor expressed on myeloid cells 1 is a hallmark of both infectious and non-infectious inflammation.
\end{abstract}

The report by Isibasi's team published in the present issue of Critical Care shows that the enhanced expression of triggering receptor expressed on myeloid cells 1 (TREM-1) on circulating monocytes in patients with acute pancreatitis is independent of the occurrence of infection [1]. This study further illustrates the difficulty of defining soluble or cell surface markers that would allow delimiting a neat border between infection and sterile or non-infectious inflammation. The recently characterized damage (or danger)-associated molecular patterns that emerged from the theory of danger model proposed by Matzinger [2], and the pathogen-associated molecular patterns that came to light after the revised definition of innate immunity by Janeway [3], are the key elements that unify infectious and non-infectious inflammation. Indeed, the fact that the same Toll-like receptors (TLRs) and NOD-like receptors recognize both damage (or danger)associated molecular patterns and pathogen-associated molecular patterns explains how similar cascades of events are occurring during inflammation independently of infection.

TREM-1 was first identified in sepsis [4], and its released form (soluble TREM-1) has been long claimed as a marker of infection [5]. Recent investigations, however, have shown that soluble TREM-1 levels or TREM-1 membrane expression is also enhanced in patients with non-infectious inflammatory disorders, such as chronic obstructive pulmonary disease [6], and in resuscitated patients after cardiac arrest [7] or after cardiac or abdominal surgery $[7,8]$. TREM-1 is a key actor of the inflammatory process. Anti-TREM-1 antibodies have been used to mimic TREM-1 ligand, which remains to be fully characterized. Not only do these antibodies activate monocytes and neutrophils to produce cytokines [9], but they also act in synergy with TLR4, TLR3, and NOD-like receptor ligands $[10,11]$. TREM-1 surface expression is upregulated by endotoxin [4] and NOD-like receptor ligands [11]. Since endotoxin translocation has been reported in many different clinical settings, including pancreatitis [12], one can suggest in some of the non-infectious diseases that - in addition to damage (or danger)-associated molecular patterns - endotoxin and some other pathogen-associated molecular patterns could be responsible for the reported increased expression of soluble TREM-1 or membrane TREM-1.

Ferat-Osorio and colleagues [1] complete the demonstration by Wang and colleagues who had previously reported the enhanced expression of TREM-1 mRNA in leukocytes of patients with pancreatitis [13], and the report by Yasuda and colleagues who showed enhanced levels of soluble TREM-1 in the same group of patients [14]. In these studies, TREM-1 mRNA expression and levels of circulating soluble TREM-1 were associated with the disease severity and organ dysfunction. In contrast, the expression of TREM-1 on monocytes was neither related to the severity of pancreatitis nor to mortality [1]. A possible explanation is the inclusion of only acute pancreatitis in Ferat-Osorio and colleagues' study while the study on mRNA also included mild pancreatitis. The discrepancy with mRNA expression could be further explained by post-transcriptional mechanisms, since an upregulation of membrane expression was reported to occur independently of mRNA synthesis [15]. Finally, another

$\mathrm{IL}=$ interleukin; TLR $=$ Toll-like receptor; TREM-1 = triggering receptor expressed on myeloid cells 1. 
explanation may be that the analysis of mRNA was performed on blood leukocytes, whereas that of its membrane expression was investigated on monocytes.

Accordingly, it would be of great interest to investigate the level of expression of TREM-1 on circulating neutrophils. The discrepancy between monocyte surface expression and soluble TREM-1 in terms of severity of the disease may reflect the unknown respective contribution of neutrophils and monocytes to the soluble form of TREM-1. As a function of the severity of the pancreatitis, the release of the membrane form of TREM-1 could reflect the level of its expression on the surface of neutrophils. Alternatively, another possible mechanism could be an enhanced release of the cell surface expression of TREM-1 from monocytes as a reflection of the severity of acute pancreatitis, while the enhanced mRNA expression sustains an enhanced level of cell surface expression. Ferat-Osorio and colleagues also studied other parameters that are known to be upregulated during inflammation, such as IL-6 and IL-10, or to be downregulated, such as the expression of HLA-DR on monocytes [1]. Interestingly, and in contrast with membrane TREM-1, these makers could allow discriminating between mild and severe acute pancreatitis.

In conclusion, the study of Isibasi's team further illustrates the overlapping processes during infectious and non-infectious inflammation, and demonstrates for the first time the enhanced expression of TREM-1 on the surface of monocytes in pancreatitis [1]. It remains to be demonstrated whether the TREM-1 ligand is present in plasma of these patients or is expressed on the surface of other cells - in order to conclude on the key role played by membrane TREM-1 during acute pancreatitis, contributing to the systemic inflammatory response syndrome that characterizes this disease.

\section{Competing interests}

The author declares that they have no competing interests.

\section{References}

1. Ferat-Osorio E, Wong-Baeza I, Esquivel-Callejas N, FigueroaFigueroa S, Duarte-Rojo A, Guzmán-Valdivia-Gómez G, RodeaRosas H, Torres-González T, Sánchez-Fernández P, Arriaga-Pizano L, López-Macías C, Robles-Díaz G, Isibasi A: Triggering receptor expressed on myeloid cells-1 expression on monocytes is associated with inflammation but not with infection in acute pancreatitis. Crit Care 2009, 13:R69.

2. Matzinger P: Tolerance, danger, and the extended family. Annu Rev Immunol 1994, 12:991-1045.

3. Janeway CA Jr: Presidential Address to The American Association of Immunologists. The road less traveled by: the role of innate immunity in the adaptive immune response. $J$ Immunol 1998, 161:539-544.

4. Bouchon A, Facchetti F, Weigand MA, Colonna M: TREM-1 amplifies inflammation and is a crucial mediator of septic shock. Nature 2001, 410:1103-1107.

5. Gibot S, Kolopp-Sarda MN, Béné MC, Cravoisy A, Levy B, Faure GC, Bollaert PE: Plasma level of a triggering receptor expressed on myeloid cells-1: its diagnostic accuracy in patients with suspected sepsis. Ann Intern Med 2004, 141:9-15.

6. Radsak MP, Taube C, Haselmayer P, Tenzer S, Salih HR, Wiewrodt R, Buhl R, Schild H: Soluble triggering receptor expressed on myeloid cells 1 is released in patients with stable chronic obstructive pulmonary disease. Clin Dev Immuno/ 2007 [article ID 5204].

7. Adib-Conquy M, Monchi M, Goulenok C, Laurent I, Thuong M, Cavaillon JM, Adrie C: Increased plasma levels of soluble triggering receptor expressed on myeloid cells 1 and procalcitonin after cardiac surgery and cardiac arrest without infection. Shock 2007, 28:406-410.

8. González-Roldán N, Ferat-Osorio E, Aduna-Vicente R, WongBaeza I, Esquivel-Callejas N, Astudillo-de la Vega H, Sánchez-Fernández P, Arriaga-Pizano L, Villasís-Keever MA, López-Macías C, Isibasi $A$ : Expression of triggering receptor on myeloid cell 1 and histocompatibility complex molecules in sepsis and major abdominal surgery. World J Gastroenterol 2005, 11: 7473-7479.

9. Bouchon A, Dietrich J, Colonna M: Cutting edge: inflammatory responses can be triggered by TREM-1, a novel receptor expressed on neutrophils and monocytes. J Immunol 2000 , 164:4991-4995.

10. Bleharski JR, Kiessler V, Buonsanti C, Sieling PA, Stenger S Colonna $\mathrm{M}$, Modlin RL: A role for triggering receptor expressed on myeloid cells-1 in host defense during the early-induced and adaptive phases of the immune response. $J$ Immunol 2003, 170:3812-3818.

11. Netea MG, Azam T, Ferwerda G, Girardin SE, Kim SH, Dinarello CA: Triggering receptor expressed on myeloid cells-1 (TREM-1) amplifies the signals induced by the NACHT-LRR (NLR) pattern recognition receptors. J Leukoc Biol 2006, 80:14541461.

12. Windsor JA, Fearon KC, Ross JA, Barclay GR, Smyth E, Poxton I, Garden OJ, Carter DC: Role of serum endotoxin and antiendotoxin core antibody levels in predicting the development of multiple organ failure in acute pancreatitis. Br J Surg 1993, 80:1042-1046.

13. Wang DY, Qin RY, Liu ZR, Gupta MK, Chang Q: Expression of TREM-1 mRNA in acute pancreatitis. World J Gastroenterol 2004, 10:2744-2746

14. Yasuda T, Takeyama Y, Ueda T, Shinzeki M, Sawa H, Takahiro N, Kamei K, Ku Y, Kuroda Y, Ohyanagi H: Increased levels of soluble triggering receptor expressed on myeloid cells- 1 in patients with acute pancreatitis. Crit Care Med 2008, 36:20482053.

15. Wong-Baeza I, González-Roldán N, Ferat-Osorio E, EsquivelCallejas N, Aduna-Vicente R, Arriaga-Pizano L, Astudillo-de la Vega H, Villasis-Keever MA, Torres-González R, Estrada-García I, López-Macias C, Isibasi A: Triggering receptor expressed on myeloid cells (TREM-1) is regulated post-transcriptionally and its ligand is present in the sera of some septic patients. Clin Exp Immunol 2006, 145:448-455. 